\title{
Plasmodium vivax multidrug resistance-1 gene polymorphism in French Guiana
}

Emilie Faway ${ }^{1,2}$, Lise Musset ${ }^{1,3,4}$, Stéphane Pelleau ${ }^{1,3,4}$, Béatrice Volney ${ }^{1,3,4}$, Jessica Casteras ${ }^{1,3}$, Valérie Caro ${ }^{5}$, Didier Menard ${ }^{6,7}$, Sébastien Briolant ${ }^{1,8,9}$ and Eric Legrand ${ }^{1,3,4,10,11^{*} \text { (i) }}$

\begin{abstract}
Background: Plasmodium vivax malaria is a major public health problem in French Guiana. Some cases of resistance to chloroquine, the first-line treatment used against P. vivax malaria, have been described in the Brazilian Amazon region. The aim of this study is to investigate a possible dispersion of chloroquine-resistant $P$. vivax isolates in French Guiana. The genotype, polymorphism and copy number variation, of the P. vivax multidrug resistance gene-1 (pvmdr1) have been previously associated with modification of the susceptibility to chloroquine.
\end{abstract}

Methods: The pvmdr1 gene polymorphism was evaluated by sequencing and copy number variation was assessed by real-time PCR, in P. vivax isolates obtained from 591 symptomatic patients from 1997 to 2013.

Results: The results reveal that 1.0\% [95\% Cl 0.4-2.2] of French Guiana isolates carry the mutations Y976F and F1076L, and that the proportion of isolates with multiple copies of pvmdr1 has significantly decreased over time, from $71.3 \%$ $(\mathrm{OR}=6.2$ [95\% Cl 62.9-78.7], $\mathrm{p}<0.0001)$ in 1997-2004 to 12.8\% ( $\mathrm{OR}=0.03$ [95\% Cl 9.4-16.9], $\mathrm{p}<0.0001)$ in 20092013. A statistically significant relationship was found between Guf-A (harboring the single mutation T958M) and Sal-1 (wild type) alleles and pvmdr1 copy number.

Conclusions: Few P. vivax isolates harboring chloroquine-resistant mutations in the pvmdr1 gene are circulating in French Guiana. However, the decrease in the prevalence of isolates carrying multiple copies of pvmdr1 might indicate that the P. vivax population in French Guiana is evolving towards a decreased susceptibility to chloroquine.

\section{Background}

Plasmodium vivax remains the most geographically widespread of the five Plasmodium species infecting humans. As the second most common cause of malaria worldwide, $P$. vivax is the main cause of malaria in South America, where 390,000 cases were reported by the World Health Organization in 2015 [1]. Approximately $95 \%$ of these $P$. vivax malaria cases occur in nine countries of the Amazon Basin, namely Brazil, Bolivia, Colombia, Ecuador, French Guiana, Guyana, Peru, Suriname and Venezuela [1]. A total of $311 P$. vivax cases were reported in French Guiana in 2014, representing $70 \%$ of the total number of malaria cases [2]. Since 1995,

\footnotetext{
*Correspondence: eric.legrand@pasteur.fr

${ }^{11}$ Genetics and Genomics of Insect Vectors Unit, Institut Pasteur, Paris, France

Full list of author information is available at the end of the article
}

the treatments of uncomplicated P. falciparum malaria, mefloquine or halofantrine were used in monotherapy until 2002 when they were replaced by the association atovaquone-proguanil and in 2009 by the combination of artemether-lumefantrine [2-4]. Like the other countries across the continent, chloroquine is still recommended as the first-line treatment for $P$. vivax in French Guiana.

In 1989, the first cases of chloroquine-resistant $P$. vivax infection were reported in Papua New Guinea [5]. First cases of $P$. vivax resistance to chloroquine in South America were described in clinical studies of unsupervised chloroquine treatment in 1989 and 1992, in Colombia and Brazil, respectively [6, 7]. It was only in 1996 that the first confirmed clinical case of resistance was described in Brazil [8]. Chloroquine resistance has spread around the world over the last decade [9], and is now found in Southeast Asia [10-14] but also in Africa [15, 
16], South America [8, 17-22] and the Middle East [23, 24].

Polymorphisms in pvmdr1 gene ( $P$. vivax multidrug resistance-1 gene, PVX_080100), orthologous to $p f m d r 1$ gene in Plasmodium falciparum (PF3D7_0523000) [25], has been associated with chloroquine resistance in many studies. Pvmdr1 Y976F and F1076L mutations are found in all malaria-endemic regions where chloroquine is used as the first-line treatment [13, 14, 26, 27]. Isolates bearing only F1076L mutations were identified but were not associated with a chloroquine resistance [28, 29]. This observation supports the argument that $P$. vivax chloroquine resistance requires the presence of both mutations. It has been suggested that $\mathrm{F} 1076 \mathrm{~L}$ is the prerequisite for the secondary acquisition of Y976F, which is responsible for the decrease in chloroquine susceptibility [29]. However, no other studies have observed this correlation between Y976F mutation and resistance phenotype $[15,18]$. Several studies have pinpointed an increase in pvmdr1 gene copy number, which seems to be related to an increased susceptibility to chloroquine [13, 14, 30,31]. Furthermore, a recent study suggested that chloroquine resistance and clinical severity in vivax malaria were associated with increased expression levels of $p v m d r 1$ and pvcrt-o genes [32].

This study aims to estimate the possible emergence of chloroquine-resistant $P$. vivax in French Guiana. The work is divided into two parts. Firstly, $p v m d r 1$ gene polymorphism and copy number were assayed in $P$. vivax isolates obtained from blood samples of patients collected since 1997 and the temporal evolution of pvmdr1 gene polymorphism and copy number were studied.

\section{Methods}

\section{Sample collection}

Between 1997 and 2013, samples were collected from 591 symptomatic patients presenting with malaria symptoms at health centres in French Guiana. Plasmodium vivax mono-infections were diagnosed by rapid diagnostic tests and/or microscopic examination of the blood. Blood samples were collected in EDTA-coated tubes and sent to the National Reference Centre (NRC) for Malaria at the Institut Pasteur de la Guyane for further analysis and biobanking.

\section{DNA extraction, amplification and sequencing}

Parasite DNA was extracted from whole blood samples using the QIAamp DNA Blood Mini Kit (Qiagen, Courtaboeuf, France), following manufacturer's instructions. The pvmdr1 gene was amplified and sequencing using protocol (primers and amplification condition) previously described by Lekweiry et al. [33] except the polymerase, $0.025 \mathrm{U} / \mu \mathrm{l}$ of Ampli Taq Gold ${ }^{\mathrm{TM}}, 2.5 \mathrm{mM} \mathrm{MgCl}_{2}$,
1× PCR Gold Buffer (Applied Biosystems). The amplification product was loaded on a $1.5 \%$ agarose gel and visualized after electrophoresis.

Sequencing of pvmdr1 PCR product was performed by using the nested primers [33] generating a product length of $547 \mathrm{bp}$ (region between codon 931 and 1095). These sequence were compared with the reference sequence Sal-1 (Genbank accession number AY571984).

\section{Pvmdr1 and pvaldolase cloning}

As a reference sample with a known $p v m d r 1$ copy number was not available, two reference plasmids containing one copy of the pvmdr1 and pvaldolase genes were generated, respectively, to use as positive controls for the real-time PCR (qPCR). They were created by PCR amplification of pvmdr1 and pvaldolase genes using A380 and A379 or A382 and A383 primers, respectively (Table 1). Each PCR product was cloned in $\mathrm{pCR}^{\mathrm{TM}} 4-\mathrm{TOPO}^{\circledR}$ plasmid using the TOPO ${ }^{\circledR}$ TA Cloning ${ }^{\circledR}$ kit (Invitrogen), following manufacturer's protocol.

\section{Real-time PCR to quantify the pvmdr1 gene copy number}

The pvmdr1 gene copy number was measured by performing a $\mathrm{qPCR}$ in comparison to the reference gene pvaldolase, using the method previously described by Lekweiry et al. [33]. The reproducibility problems encountered were solved by designing new probes using Primer Express ${ }^{\circledR}$ software (Applied Biosystems). These primers and probes are listed in Table 1 . The qPCR was carried out in a $25 \mu \mathrm{l}$ reaction volume containing $1 \mu \mathrm{l}$ of DNA, $300 \mathrm{nM}$ of each primer, $200 \mathrm{nM}$ of probe, $12.5 \mu \mathrm{l}$ of TaqMan ${ }^{\circledR}$ Universal Master Mix II (Applied Biosystems) and water. Real-time PCR was performed under the following conditions: $95{ }^{\circ} \mathrm{C}$ for $10 \mathrm{~min}$, then 40 cycles at $95^{\circ} \mathrm{C}$ for $15 \mathrm{~s}$ and $65^{\circ} \mathrm{C}$ for $1 \mathrm{~min}$. Samples were set up in triplicate and experiments were repeated independently twice.

Results analysis was executed by StepOne ${ }^{\mathrm{TM}}$ software (Applied Biosystems). The signal from the pvmdr1 gene was normalized to the single copy pvaldolase reference gene, then copy number was determined using the mathematical model described by Pfaffl [34].

\section{Statistical analysis}

All statistical analyses were performed with $\mathrm{R}$ software (version 3.0.2). Percentages were calculated for each parameter studied, namely single nucleotide polymorphisms and increased pvmdr1 copy number, in comparison to the total sample size. Corresponding $95 \%$ confidence intervals (CI) were calculated using the exact (Clopper-Pearson interval) method [35]. In this study, the pvmdr1 copy number was analysed as a qualitative variable and two groups were considered: samples with one 
copy and samples with at least two copies of the pvmdr1 gene.

A Chi square test for trend allowed comparison of the temporal evolution of $p v m d r 1$ allele frequencies and gene copy number. A logistic regression was used to determine the association between polymorphisms and the $p v m d r 1$ gene copy numbers. A p value below 0.05 was considered significant.

\section{Nucleotide sequence accession numbers}

The Guf-A, Guf-B and Guf-C allele sequences of the pvmdr1 gene reported in this study were deposited in GenBank under accession numbers KU196660, KU196661 and KU196662, respectively.

\section{Results}

\section{Demographic information}

A total of 547 patients for 591 sample, 362 men and 185 women with the sex ratio of 1.96 , were included in this study. The average age was 29.2 years (1 month to 76 years, including 88 children under 15 years) with parasitaemia between 0.001 and $4 \%$ with an average of $0.32 \%$ (Table 2). Three time periods (1997-2004, 2005-2008 and 2009-2013) were considered according to the years 2005 when the $P$. vivax became the dominant species diagnosed in French Guiana, and 2009 when the combination of artemether and lumefantrine was adopted for the treatment of $P$. falciparum and mixed infections $(P$. falciparum/P. vivax) in French Guiana (Table 2). No significant association on all parameters (age, sex ratio and parasitaemia) and the time period.

\section{Polymorphism of the pvmdr1 gene}

Among the 591 genotyped samples, four non-synonymous mutations (T958 M, Y976F, F1070L and F1076L) and one synonymous mutation (L1022L) were identified. The French Guiana strains were then divided into four alleles (Fig. 1). The Sal-1 wild-type allele was present in $11.2 \%(\mathrm{n}=66 / 591$, CI 95\% [8.7-14.0]) of the samples while 86.5\% ( $\mathrm{n}=511 / 591$, CI 95\% [83.4-89.1]) of isolates carried the T958 M mutation and this predominant allele was called Guf-A. Only $1.4 \%$ $(\mathrm{n}=8 / 591$, CI 95\% [0.6-2.7]) of isolates carried the T958M/ F1070L mutations and this double mutant allele was referenced as Guf-B. Finally, 1.0\% $(n=6 / 591$, CI 95\% [0.4-2.2] of isolates carried the T958M/Y976F/F1076L, this triple mutant was named Guf-C (Fig. 1).

The temporal evolution of these alleles was then determined (1997-2004, $\mathrm{n}=136 ; 2005-2008, \mathrm{n}=120$ and 2009-2013, $\mathrm{n}=335$; Fig. 2). No significant association was found between the frequency of Guf-B and Guf-C alleles and the time period $(p=0.44$ and $p=0.35$, respectively, Chi square test for trend). A statistically significant increase in the frequency of the Sal-1 allele through time $(\mathrm{p}<0.0001)$ has detected, along with a statistically significant decrease for the Guf-A allele ( $<$ 0.002) (Fig. 2). Furthermore, relationship between epidemiological data and genotype was not observed.

\section{Relationship between copy number and genotype of the pvmdr1 gene}

The copy number of the pvmdr1 gene was determined for all samples and varied from 1 to 8 (mean 1.45, CI 95\% [1.35-1.55]). The majority of the sample, $68.5 \%$

Table 1 Primers and probes for quantification of the pvmdr1 copy number by qPCR

\begin{tabular}{lll}
\hline Primer and probe name & Sequence & Gene \\
\hline A380 & 5'-GAG-AGG-ACG-TAA-ACG-TGC-TT-3' & pvmdr1 \\
A379 & 5'-ACG-TTG-GTG-TCG-TAC-TGA-TTC-G-3' & \\
A399 & 5'-FAM_TTT-GCC-GCA-ATT-GA_MGB/NFQ-3' \\
A382 & 5'-AGT-TTT-GTT-GGA-AGG-AGC-TTT-ATT-G-3' \\
A383 & 5'-TGG-TTT-TCA-CAG-CAC-AGT-CGT-AT-3' & pvaldolase \\
A397 & 5'-FAM_CCC-AAC-ATG-GTG-ACC-G_MGB/NFQ-3' \\
\hline
\end{tabular}

MGB/NFQ minor groove binder/non-fluorescent quencher, pvmdr1 Plasmodium vivax multi-drug resistance 1

Table 2 Demographic information

\begin{tabular}{|c|c|c|c|c|c|c|}
\hline Year & $\begin{array}{l}\text { Number } \\
\text { of patient }\end{array}$ & Age (mini-max) & Nb men & Nb women & Sex ratio & $\begin{array}{l}\text { Parasitemia \% } \\
\text { (mini-max) }\end{array}$ \\
\hline 1997-2004 & 136 & $26.7(0.46-56)$ & 85 & 50 & 1.7 & $0.4(0.01-2)$ \\
\hline $2005-2008$ & 120 & $22.9(0.08-63)$ & 82 & 38 & 2.16 & $0.5(0.01-4)$ \\
\hline 2009-2013 & 291 & $31.2(0.67-76)$ & 195 & 97 & 2.01 & $0.3(0.001-2.3)$ \\
\hline Total & 547 & $29.2(0.08-76)$ & 362 & 185 & 1.96 & $0.32(0.001-4)$ \\
\hline
\end{tabular}

Age were indicated in year; the parasitemia were indicated on percentage of red blood cell infected by $P$. vivax 


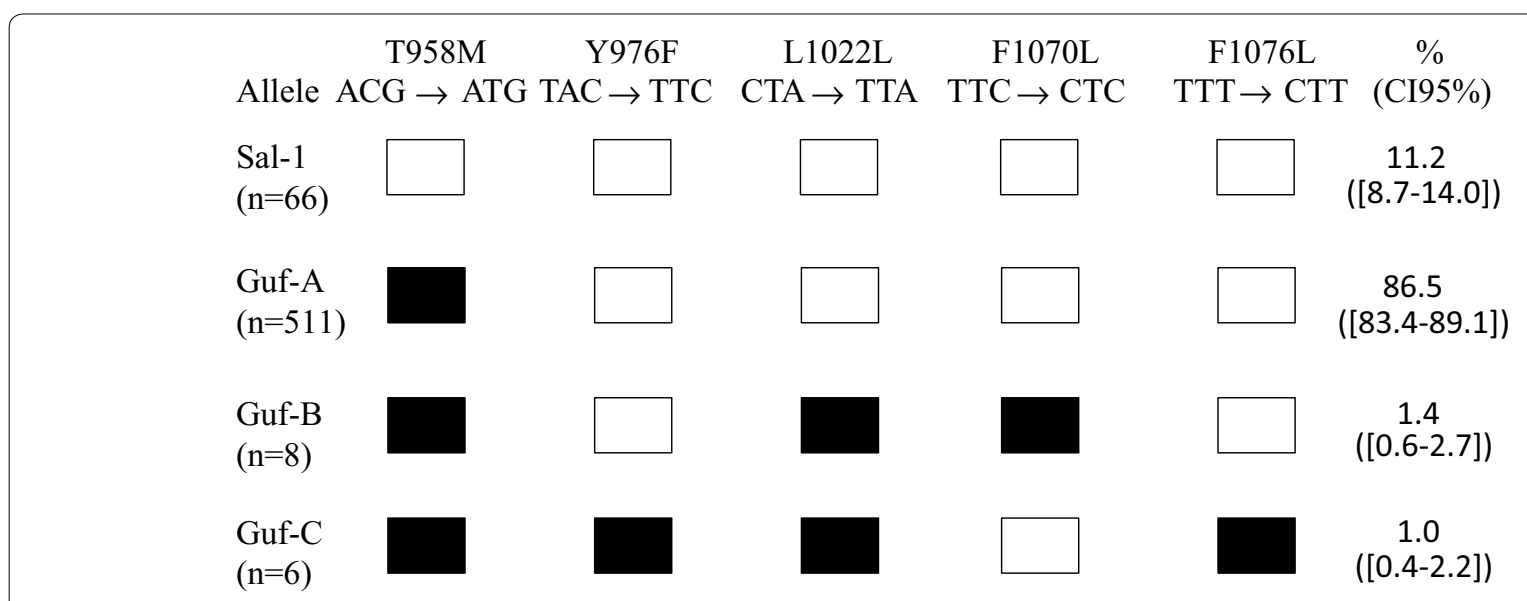

Total $(\mathrm{n}=591)$

Fig. 1 Pvmdr1 sequence polymorphism (codon 931-1095) of 591 isolates collected in French Guiana between 1997 and 2013. Only polymorphic codons are indicated. Open symbols denote the wild-type (Sal-1-type) nucleotide sequence, and blacksymbols indicate the presence of the mutant sequence shown at the top. The number of isolates observed for each allele is indicated in brackets

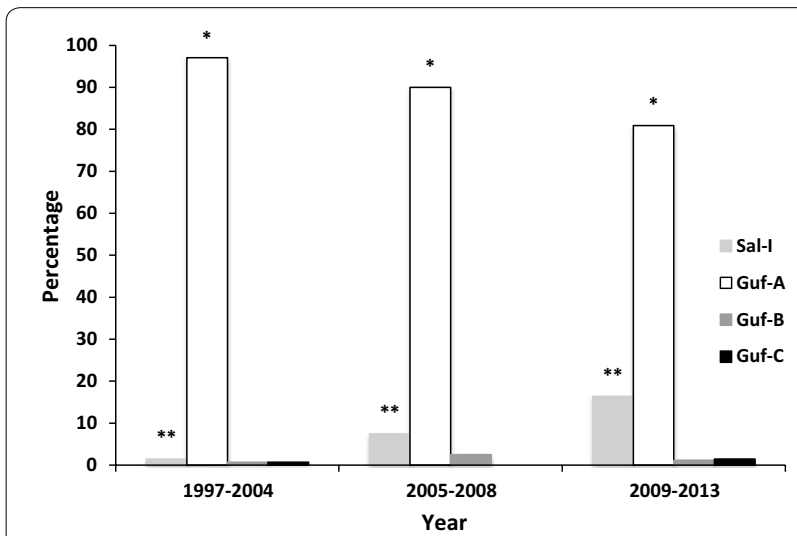

Fig. 2 Temporal evolution of pvmdr1 allele frequencies. ${ }^{*} p<0.0002$ and ${ }^{* *} p<0.0001$ denote significant differences in allele frequencies through time (Chi square test for trend)

( $\mathrm{n}=405 / 591$, CI 95\% [64.6-72.3]), had one copy while $31.5 \%(\mathrm{n}=186 / 591$, CI 95\% [27.7-35.4]) had two to eight copies. The frequency of isolates with multiple copies of the pvmdr1 gene was significantly higher in samples collected between 1997 and 2004 (97/136, 71.3\%, CI 95\% [62.9-78.7]) than in samples from 2005 to $2008(45 / 120$, $37.5 \%$, CI 95\% [28.8-46.8]) or even after 2008 (43/335, $12.8 \%$, CI 95\% [9.4-16.9]). This decrease over time was statistically significant $(\mathrm{p}<0.0001$, Chi square test for trend, see Fig. 3). Moreover, relationship between epidemiological data and copy number was not observed.

The association between the copy number and genotype of the pvmdr1 gene was evaluated. The proportion of isolates harbouring multiple copies was not equally distributed among the different alleles. A statistically significant

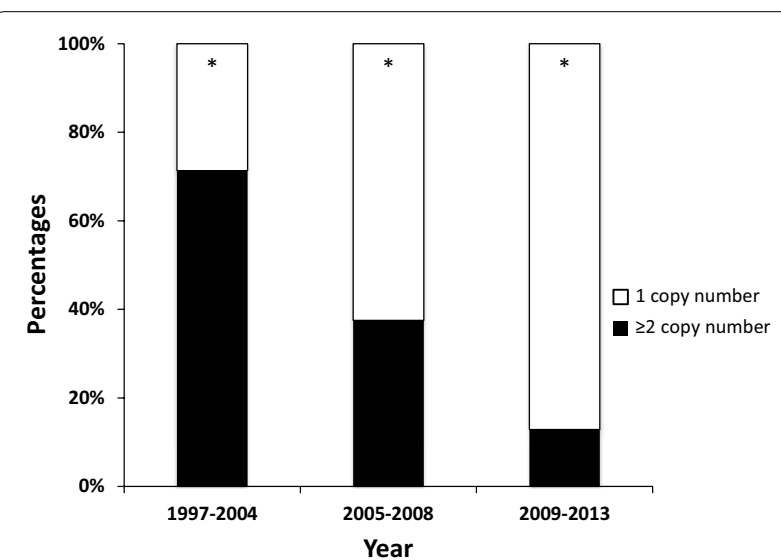

Fig. 3 Temporal evolution of the proportion of isolates harbouring single or multiple pvmdr1 copy number. White represents the isolates with single copy number of pvmdr 1 gene, and black indicates isolates with two or more pvmdr 1 copy numbers. ${ }^{*} p<0.0001$ for Chi square test for trend

association was found between the Sal-1 allele and single copy $p v m d r 1$ gene $(\mathrm{p}=0.0006)$ as well as between the Guf-A allele and copy number greater than $1(\mathrm{p}=0.0002)$. No statistically significant relationship was found between the Guf-B and Guf-C alleles and the pvmdr1 gene copy number ( $\mathrm{p}=0.93$ and $\mathrm{p}=0.58$, respectively, Fig. 4 ).

\section{Discussion}

Vivax malaria is a major public health problem in South America. In French Guiana, it is currently responsible for two-thirds of malaria cases. Resistance to chloroquine, the main treatment used against vivax malaria [2], has been reported in the Brazilian Amazon Region [4, 17, 18, 


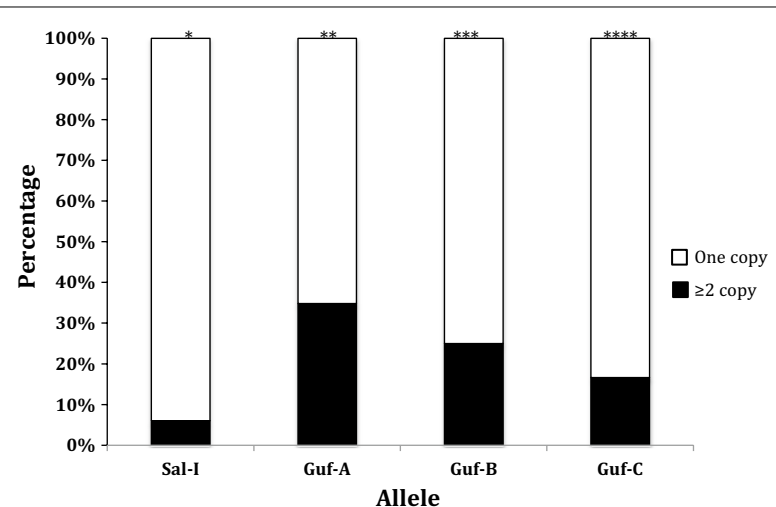

Fig. 4 Evaluation of the relationship between pvmdr1 copy number and genotype. ${ }^{*} \mathrm{OR}=0.12$ [95\% Cl 0.04-0.034], $\mathrm{p}=0.00006$. ${ }^{*} \mathrm{O} \mathrm{OR}=5.57[95 \% \mathrm{Cl} 2.51-12.36], \mathrm{p}=0.00002 .{ }^{* *} \mathrm{OR}=0.73[95 \% \mathrm{Cl}$ $0.15-3.64], p=0.70 .{ }^{* * *} \mathrm{OR}=0.44[95 \% \mathrm{Cl} 0.05-3.76], p=0.45$

20, 21, 32, 36, 37]. In French Guiana, the development of gold-mining activities and the consequent human migration between French Guiana and neighbouring countries, Brazil and Suriname [4, 38, 39], have raised fears that chloroquine-resistant $P$. vivax isolates may spread. It is therefore important to follow the circulation of resistant isolates. There are previous studies suggesting that $\mathrm{Y} 976 \mathrm{~F}$ and F1076L mutations in the pvmdr1 gene are associated with in vitro resistance to chloroquine [13, 14]. Pvmdr1 Y976F mutation alone is not sufficient to cause the failure of chloroquine treatment, as observed in Madagascar [15], Brazil [21] and Honduras [40]. It can only affect treatment outcome when associated with the F1076L mutation. In French Guiana, these two mutations were carried by $1.0 \%$ of the isolates (i.e., Guf-C allele). Therefore, these parasites could potentially be resistant to chloroquine; however, an association with clinical drug response or in vitro susceptibility have not been investigated. This value is similar to the $1.8 \%$ prevalence reported in Brazil [41].

Sal-1 and Guf-A alleles were present in 11.2 and 86.5\% of the samples in French Guiana, respectively, showing significant and inverse trends in the temporal evolution of their frequency; while the frequency of the Sal-1 allele significantly increased over time, the frequency of the Guf-A allele decreased. These temporal variations of allele frequencies could be explained by different factors, such as the increased circulation of isolates between French Guiana and Brazil or changes in drug policy for the treatment of $P$. falciparum. This is supported by a recent study showing that the T958M mutation allele is the majority among Brazilian isolates collected between 2010 and 2014 [42]. Many studies in Southeast Asia have shown that isolates with $p v m d r 1$ gene amplification were characterized by increased susceptibility to chloroquine but decreased susceptibility to mefloquine [13,
31]. A significant decrease of the proportion of isolates with multiple copies of pvmdr1 over this 16-year study period has been found, decreasing from $71.3 \%$ between 1997 and 2004 to only $12.8 \%$ between 2009 and 2013 . A recent study comparing $P$. vivax isolates from French Guiana (collected between 2001 and 2003) and Southeast Asia (collected in 2010) showed the number of isolates with multiple copies of $p v m d r 1$ gene to be higher in French Guiana than in Cambodia [43]. Moreover, pvmdr1 gene amplifications were rare (fewer than 2\%) in countries where mefloquine has never been used for malaria treatment, such as Madagascar and Sudan [43]. In P. falciparum, multiple copies of $p f m d r 1$ were associated with mefloquine-resistant isolates [44]. This has been confirmed in French Guiana where isolates with amplified copy number of $p f m d r 1$ gene were significantly correlated with resistance to mefloquine and halofantrine, both used in monotherapy against uncomplicated P. falciparum malaria until 2002 [45]. P. vivax isolates were therefore subjected to indirect selection pressure by mefloquine during the treatment of $P$. falciparum or mixed infections (P. falciparum and P. vivax). When the use of mefloquine and halofantrine ceased in French Guiana, $P$. falciparum isolates with one copy of $p f m d r 1$ increased [45]. This loss of selective pressure would also explain the increased frequency of $P$. vivax isolates with a single copy of the pvmdr1 gene, a genotype associated to chloroquine resistance [13].

Recently two studies analyzing the whole genome sequences of isolates collected in America, Africa and Asia, have shown great diversity of $P$. vivax isolates according to their geographical origin in particular for malaria drug antifolate resistance genes involved in resistance to ( $p v d h f r$ and $p v d h p s)[46,47]$. Nevertheless, the role of pvmdr1 in conferring resistance to chloroquine is still elusive and controversial and was recently further challenged by global population genomic studies of $P$. vivax. Indeed, Schousboe et al. studied the prevalence of polymorphisms and the diversity in microsatellite markers flanking the $p v m d r 1$ gene in $P$. vivax isolates from seven endemic countries worldwide (Pakistan, Afghanistan, Nepal, Sri Lanka, Ecuador, Sao Tomé and Sudan). Although they showed that Y976F and F1076L mutations in pvmdr1 gene have developed on multiple haplotype backgrounds by convergent evolution in these countries, they highlighted high levels of diversity around mutant alleles, suggesting these alleles were not subject to a selective sweep [48].

\section{Conclusions}

The present study indicates that $P$. vivax isolates with mutations in pvmdr1 previously described as associated with chloroquine resistance are present at low frequency in 
French Guiana. In addition, the number of copies of the gene decreases over time. A continuous surveillance of these genetic markers in the $P$. vivax population circulating in this region should be maintained to ensure public health.

\begin{abstract}
Authors' contributions
EF and EL carried out the molecular genetic studies; EF, EL and SB analysed the data; JC, EL, LM, SP and BV confirmed the diagnostic and updated the biobank collection; EL and LM supervised, carried out and coordinated field collections of patient isolates; LM, SB and EL conceived and coordinated the study; VC carried out the sequencing of PCR products; DM realized the sequencing and APCR of sample collected between 2000 and 2003; EF, SB, SP, LM and EL drafted the manuscript. All authors read and approved the final manuscript.
\end{abstract}

\section{Author details}

1 Laboratoire de Parasitologie, Institut Pasteur de la Guyane, Cayenne, French Guiana. ${ }^{2}$ URPhyM-NARILIS, University of Namur, Namur, Belgium. ${ }^{3}$ National Reference Center for Malaria, Institut Pasteur de la Guyane, Cayenne, French Guiana. ${ }^{4}$ World Health Organization Collaborating Center for Surveillance of Antimalarial Drug Resistance, Institut Pasteur de la Guyane, Cayenne, French Guiana. ${ }^{5}$ Environment and Infectious Risks unit, Genotyping of Pathogens Pole, Institut Pasteur, Paris, France. ${ }^{6}$ Malaria Molecular Epidemiology Unit, Institut Pasteur in Cambodia, Phnom Penh, Cambodia. ${ }^{7}$ Malaria Translational Research Unit, Institut Pasteur in Cambodia, Phnom Penh, Cambodia. ${ }^{8}$ Direction Interarmées du Service de Santé, Cayenne, French Guiana.

${ }^{9}$ Institut de Recherche Biomédicale des Armées, Brétigny sur Orge, France.

${ }^{10}$ Malaria Translational Research Unit, Institut Pasteur, Paris, France. ${ }^{11}$ Genetics and Genomics of Insect Vectors Unit, Institut Pasteur, Paris, France.

\section{Acknowledgements}

The authors are grateful to Cayenne Hospital, Saint-Laurent du Maroni Hospital, the Health Centre coordination and all partners working in the diagnosis centres for their help collecting materials and data. The authors also thank the Institut Pasteur Clinical Research Department (PIRC) for the clinical research regulatory review.

\section{Competing interests}

The authors declare that they have no competing interests.

\section{Availability of data and materials}

All data and material presented in this article are made available, unless otherwise stated.

\section{Consent for publication}

All authors approved the manuscript.

\section{Ethics approval and consent to participate}

All the samples analysed in the study came from blood collections required by standard medical care for any patient presenting fever on admission to hospital in French Guiana. According to French legislation (Article L.1211-2 and related, French Public Health Code), biobanking and the secondary use of remaining human clinical samples for scientific purposes are possible if the corresponding patient is informed and has not objected to such use. This requirement was fulfilled for the present study: each patient was informed via the hospital brochure entitled Information for Patients, and no immediate or delayed patient opposition was reported to the Malaria NRC by the clinicians. Moreover, in application of French legislation (Article L.1243-3 and related, French Public Health Code), samples received at the Malaria NRC had been registered for use in research in the NRC biobank, which was declared to and approved by the French Ministry for Research and a French Ethics Committee before its registration under declaration number DC-2010-1223; collection Nu2. French legislation does not require institutional review board approval.

\section{Funding}

This work benefited from funding from the Institut de Veille Sanitaire (French Ministry of Health) and the French Army (Grant LR607e). SP was financed by European grant managed by the European Commission (REGPOT-CT2011-285837-STRONGER). EF was financed by the European Union (Lifelong Learning Programme).
Received: 22 June 2016 Accepted: 31 October 2016

Published online: 08 November 2016

\section{References}

1. WHO. World Malaria Report 2015. Geneva: World Health Organization; 2016. p. 1-255.

2. National Reference Centre for Malaria. National reference centre for malaria: 2014 annual activity report. Paris: National Reference Centre for Malaria; 2015.

3. Legrand E, Volney B, Meynard JB, Mercereau-Puijalon O, Esterre P. In vitro monitoring of Plasmodium falciparum drug resistance in French Guiana: a synopsis of continuous assessment from 1994 to 2005. Antimicrob Agents Chemother. 2008;52:288-98.

4. Musset L, Pelleau S, Girod R, Ardillon V, Carvalho L, Dusfour I, et al. Malaria on the Guiana Shield: a review of the situation in French Guiana. Mem Inst Oswaldo Cruz. 2014;109:525-33.

5. Rieckmann KH, Davis DR, Hutton DC. Plasmodium vivax resistance to chloroquine? Lancet. 1989:2:1183-4.

6. Arias AE, Corredor A. Low response of Colombian strains of Plasmodium vivax to classical antimalarial therapy. Trop Med Parasitol. 1989:40:21-3.

7. Garavelli PL, Corti E. Chloroquine resistance in Plasmodium vivax: the first case in Brazil. Trans R Soc Trop Med Hyg. 1992:86:128.

8. Phillips EJ, Keystone JS, Kain KC. Failure of combined chloroquine and high-dose primaquine therapy for Plasmodium vivax malaria acquired in Guyana, South America. Clin Infect Dis. 1996;23:1171-3.

9. Baird JK. Resistance to therapies for infection by Plasmodium vivax. Clin Microbiol Rev. 2009:22:508-34.

10. Dua VK, Kar PK, Sharma VP. Chloroquine resistant Plasmodium vivax malaria in India. Trop Med Int Health. 1996:1:816-9.

11. Guthmann JP, Pittet $A$, Lesage A, Imwong $M$, Lindegardh $N$, Min Lwin $M$, et al. Plasmodium vivax resistance to chloroquine in Dawei, southern Myanmar. Trop Med Int Health. 2008;13:91-8.

12. Phan GT, de Vries PJ, Tran BQ, Le HQ, Nguyen NV, Nguyen TV, et al. Artemisinin or chloroquine for blood stage Plasmodium vivax malaria in Vietnam. Trop Med Int Health. 2002;7:858-64.

13. Suwanarusk R, Chavchich M, Russell B, Jaidee A, Chalfein F, Barends M, et al. Amplification of pvmdr1 associated with multidrug-resistant Plasmodium vivax. J Infect Dis. 2008;198:1558-64.

14. Suwanarusk R, Russell B, Chavchich M, Chalfein F, Kenangalem E, Kosaisavee $V_{\text {, }}$ et al. Chloroquine resistant Plasmodium vivax: in vitro characterisation and association with molecular polymorphisms. PLoS ONE. 2007;2:e1089.

15. Barnadas C, Ratsimbasoa A, Tichit M, Bouchier C, Jahevitra M, Picot S, et al. Plasmodium vivax resistance to chloroquine in Madagascar: clinical efficacy and polymorphisms in pvmdr1 and pvcrt-o genes. Antimicrob Agents Chemother. 2008;52:4233-40.

16. Ketema T, Bacha K, Birhanu T, Petros B. Chloroquine-resistant Plasmodium vivax malaria in Serbo town, Jimma zone, south-west Ethiopia. Malar J. 2009;8:177.

17. Chehuan YF, Costa MR, Costa JS, Alecrim MG, Nogueira F, Silveira H, et al. In vitro chloroquine resistance for Plasmodium vivax isolates from the Western Brazilian Amazon. Malar J. 2013:12:226.

18. Gama BE, Oliveira NK, Souza JM, Daniel-Ribeiro CT, Ferreira-da-Cruz Mde F. Characterisation of pvmdr 1 and pvdhfr genes associated with chemoresistance in Brazilian Plasmodium vivax isolates. Mem Inst Oswaldo Cruz. 2009:104:1009-11.

19. Graf PC, Durand S, Alvarez Antonio C, Montalvan C, Galves Montoya $M$, Green MD, et al. Failure of supervised chloroquine and primaquine regimen for the treatment of Plasmodium vivax in the Peruvian Amazon. Malar Res Treat. 2012;2012:936067.

20. Marques MM, Costa MR, Santana Filho FS, Vieira JL, Nascimento MT, Brasil LW, et al. Plasmodium vivax chloroquine resistance and anemia in the western Brazilian Amazon. Antimicrob Agents Chemother. 2014;58:342-7.

21. Orjuela-Sanchez P, de Santana Filho FS, Machado-Lima A, Chehuan YF, Costa MR, Alecrim M, et al. Analysis of single-nucleotide polymorphisms in the crt-o and mdr1 genes of Plasmodium vivax among chloroquineresistant isolates from the Brazilian Amazon region. Antimicrob Agents Chemother. 2009;53:3561-4. 
22. Soto J, Toledo J, Gutierrez P, Luzz M, Llinas N, Cedeno N, et al. Plasmodium vivax clinically resistant to chloroquine in Colombia. Am J Trop Med Hyg. 2001;65:90-3.

23. Khatoon L, Baliraine FN, Bonizzoni M, Malik SA, Yan G. Prevalence of antimalarial drug resistance mutations in Plasmodium vivax and $P$. falciparum from a malaria-endemic area of Pakistan. Am J Trop Med Hyg. 2009;81:525-8.

24. Kurcer MA, Simsek Z, Kurcer Z. The decreasing efficacy of chloroquine in the treatment of Plasmodium vivax malaria, in Sanliurfa, south-eastern Turkey. Ann Trop Med Parasitol. 2006;100:109-13.

25. Foote SJ, Thompson JK, Cowman AF, Kemp DJ. Amplification of the multidrug resistance gene in some chloroquine-resistant isolates of $P$. falciparum. Cell. 1989;57:921-30.

26. Lu F, Lim CS, Nam DH, Kim K, Lin K, Kim TS, et al. Genetic polymorphism in pvmdr1 and pvcrt-o genes in relation to in vitro drug susceptibility of Plasmodium vivax isolates from malaria-endemic countries. Acta Trop. 2011;117:69-75.

27. Rungsihirunrat K, Muhamad P, Chaijaroenkul W, Kuesap J, Na-Bangchang K. Plasmodium vivax drug resistance genes; Pvmdr1 and Pvcrt-o polymorphisms in relation to chloroquine sensitivity from a malaria endemic area of Thailand. Korean J Parasitol. 2015;53:43-9.

28. Kim YK, Kim C, Park I, Kim HY, Choi JY, Kim JM. Therapeutic efficacy of chloroquine in Plasmodium vivax and the pvmdr 1 polymorphisms in the Republic of Korea under mass chemoprophylaxis. Am J Trop Med Hyg. 2011;84:532-4.

29. Orjuela-Sanchez P, Karunaweera ND, da Silva-Nunes M, da Silva NS, Scopel KK, Goncalves RM, et al. Single-nucleotide polymorphism, linkage disequilibrium and geographic structure in the malaria parasite Plasmodium vivax: prospects for genome-wide association studies. BMC Genet. 2010;11:65.

30. Fernandez-Becerra C, Pinazo MJ, Gonzalez A, Alonso PL, del Portillo HA, Gascon J. Increased expression levels of the pvcrt-o and pvmdr1 genes in a patient with severe Plasmodium vivax malaria. Malar J. 2009;8:55

31. Imwong M, Pukrittayakamee S, Pongtavornpinyo W, Nakeesathit S, Nair S, Newton $\mathrm{P}$, et al. Gene amplification of the multidrug resistance 1 gene of Plasmodium vivax isolates from Thailand, Laos, and Myanmar. Antimicrob Agents Chemother. 2008;52:2657-9.

32. Melo GC, Monteiro WM, Siqueira AM, Silva SR, Magalhaes BM, Alencar AC, et al. Expression levels of pvcrt-o and pvmdr-1 are associated with chloroquine resistance and severe Plasmodium vivax malaria in patients of the Brazilian Amazon. PLoS ONE. 2014;9:e105922.

33. Lekweiry KM, Boukhary AOMS, Gaillard T, Wurtz N, Bogreau H, Hafid JE, et al. Molecular surveillance of drug-resistant Plasmodium vivax using pvdhfr, pvdhps and pvmdr 1 markers in Nouakchott, Mauritania. J Antimicrob Chemother. 2012;67:367-74.

34. Pfaffl MW. A new mathematical model for relative quantification in realtime RT-PCR. Nucleic Acids Res. 2001;29:e45.

35. Clopper C, Pearson S. The use of confidence or fiducial limits illustrated in the case of binomial. Biometrika. 1934:26:404-13.

36. de Santana Filho FS, Arcanjo AR, Chehuan YM, Costa MR, Martinez-Espinosa FE, Vieira JL, et al. Chloroquine-resistant Plasmodium vivax, Brazilian Amazon. Emerg Infect Dis. 2007;13:1125-6.
37. Gama BE, Lacerda MV, Daniel-Ribeiro CT, Ferreira-da-Cruz Mde F. Chemoresistance of Plasmodium falciparum and Plasmodium vivax parasites in Brazil: consequences on disease morbidity and control. Mem Inst Oswaldo Cruz. 2011;106(Suppl 1):159-66.

38. Pommier de Santi V, Dia A, Adde A, Hyvert G, Galant J, Mazevet M, et al. Malaria in French Guiana linked to illegal gold mining. Emerg Infect Dis. 2016:22:344-6.

39. Pommier de Santi V, Djossou F, Barthes N, Bogreau H, Hyvert G, Nguyen C, et al. Malaria hyperendemicity and risk for artemisinin resistance among illegal gold miners, French Guiana. Emerg Infect Dis. 2016;22:903-6.

40. Jovel IT, Mejia RE, Banegas E, Piedade R, Alger J, Fontecha G, et al. Drug resistance associated genetic polymorphisms in Plasmodium falciparum and Plasmodium vivax collected in Honduras, Central America. Malar J. 2011;10:376.

41. Vargas-Rodriguez Rdel C, da Silva Bastos M, Menezes MJ, Orjuela-Sanchez $P$, Ferreira MU. Single-nucleotide polymorphism and copy number variation of the multidrug resistance-1 locus of Plasmodium vivax: local and global patterns. Am J Trop Med Hyg. 2012;87:813-21.

42. Gomes LR, Almeida-de-Oliveira NK, de Lavigne AR, de Lima SR, de PinaCosta A, Brasil P, et al. Plasmodium vivax mdr1 genotypes in isolates from successfully cured patients living in endemic and non-endemic Brazilian areas. Malar J. 2016:15:96

43. Khim N, Andrianaranjaka V, Popovici J, Kim S, Ratsimbasoa A, Benedet C, et al. Effects of mefloquine use on Plasmodium vivax multidrug resistance. Emerg Infect Dis. 2014;20:1637-44.

44. Price RN, Uhlemann AC, Brockman A, McGready R, Ashley E, Phaipun $L$, et al. Mefloquine resistance in Plasmodium falciparum and increased pfmdr1 gene copy number. Lancet. 2004;364:438-47.

45. Legrand E, Yrinesi J, Ekala MT, Peneau J, Volney B, Berger F, et al. Discordant temporal evolution of Pfcrt and Pfmdrl genotypes and Plasmodium falciparum in vitro drug susceptibility to 4-aminoquinolines after drug policy change in French Guiana. Antimicrob Agents Chemother. 2012;56:1382-9.

46. Hupalo DN, Luo Z, Melnikov A, Sutton PL, Rogov P, Escalante A, et al. Population genomics studies identify signatures of global dispersal and drug resistance in Plasmodium vivax. Nat Genet. 2016;48:953-8.

47. Pearson RD, Amato R, Auburn S, Miotto O, Almagro-Garcia J, Amaratunga $\mathrm{C}$, et al. Genomic analysis of local variation and recent evolution in Plasmodium vivax. Nat Genet. 2016;48:959-64.

48. Schousboe ML, Ranjitkar S, Rajakaruna RS, Amerasinghe PH, Morales $F$, Pearce R, et al. Multiple origins of mutations in the $m d r 1$ gene-a putative marker of chloroquine resistance in P. vivax. PLoS Negl Trop Dis. 2015;9:e0004196

\section{Submit your next manuscript to BioMed Central and we will help you at every step:}

- We accept pre-submission inquiries

- Our selector tool helps you to find the most relevant journal

- We provide round the clock customer support

- Convenient online submission

- Thorough peer review

- Inclusion in PubMed and all major indexing services

- Maximum visibility for your research

Submit your manuscript at www.biomedcentral.com/submit
C BioMed Central 